\title{
Characterizing the Performance of Ternary Concrete Mixtures Involving Slag and Metakaolin
}

\author{
Matthew S. Sullivan, Mi G. Chorzepa *(1) and Stephan A. Durham \\ College of Engineering, The University of Georgia, Athens, GA 30602, USA; \\ matthewseansullivan@hotmail.com (M.S.S.); sdurham@uga.edu (S.A.D.) \\ * Correspondence: chorzepa@uga.edu
}

Received: 17 December 2019; Accepted: 26 January 2020; Published: 31 January 2020

\begin{abstract}
Ternary blends of cementitious materials are investigated. A cement replacement level of $45 \%$ is used for all ternary mixtures consisting of $15 \%$ metakaolin and 30\% slag replacements. Three metakaolin and two blast furnace slag, referred to as 'slag' for short, products commercially available are used to compare performance in ternary blends. A mixture with a $45 \%$ fly ash replacement is included to serve as a benchmark for performance. The control mixture contains $422 \mathrm{~kg}$ of cement per cubic meter of concrete, and a water-to-cementitious material ratio of 0.43 is used for all mixtures with varying dosages of superplasticizer to retain workability. Mixtures are tested for mechanical properties, durability, and volumetric stability. Mechanical properties include compression, split-cylinder tension, modulus of rupture, and dynamic Young's modulus. Durability measures are comprised of rapid chloride-ion penetrability, sulfate resistance, and alkali-silica reactivity. Finally, the measure of dimensional stability is assessed by conducting drying shrinkage and coefficient of thermal expansion tests. Results indicate that ternary mixtures including metakaolin perform similarly to the control with respect to mechanical strength. It is concluded that ternary blends perform significantly better than both control and fly ash benchmark in tests measuring durability. Furthermore, shrinkage is reduced while the coefficients of thermal expansion are slightly higher than control and the benchmark.
\end{abstract}

Keywords: metakaolin; blast furnace slag; ternary; strength; durability; concrete; supplementary cement; pozzolan; mineral admixtures; coefficient of thermal expansion

\section{Introduction}

The use of supplementary cementitious materials (SCM) in ready-mixed concrete has seen rapid growth in North America since the 1970s [1]. Two types of chemical reactions contribute to the performance of hardened concrete mixtures incorporating SCMs. The first is the hydraulic reaction, which is the reaction of free lime $(\mathrm{CaO})$ with water produces heat, calcium silicate hydrates $(\mathrm{C}-\mathrm{S}-\mathrm{H})$, and calcium hydroxide, $\mathrm{Ca}(\mathrm{OH})_{2}$ or $\mathrm{CH}$. In mixtures containing ordinary Portland cement $(\mathrm{OPC})$, this reaction performed exclusively by the cement. However, some SCMs with significant $\mathrm{CaO}$ contents also take part in this reaction. Common SCMs take part in this reaction are Class C fly ash and blast furnace slag. The second reaction is the pozzolanic reaction, which is exhibited by SCMs with high contents of glassy silica or alumina in the presence of $\mathrm{CH}$ and water. In this reaction, amorphous (glassy) alumina or silica react with the $\mathrm{CH}$ created during hydration to produce additional C-S-H, calcium aluminate hydrates (C-A-H), or calcium aluminosilicate hydrates (C-A-S-H). In short, the additional pozzolanic and/or hydraulic reactions by SCMs tend to reduce porosity, consume non-structural $\mathrm{CH}$ (prone to leaching), and produce additional structural hydrates, all of which enhance concrete performance. 
Typically, SCMs are used as a cement-replacing material because of their ability to enhance performance, reduce costs, and reduce environmental impact. During the production of cement clinker, $\mathrm{CaCO}_{3}$ (or calcium carbonate) is converted into calcium oxide by means of calcination inside a rotary kiln [2]. The most environmentally detrimental byproduct, $\mathrm{CO}_{2}$ (carbon dioxide), is then emitted. Equation (1) presents the chemical reaction in a simplified form:

$$
\mathrm{CaCO}_{3}+\text { heat } \rightarrow \mathrm{CaO}+\mathrm{CO}_{2}
$$

Cement production is the largest emitter of $\mathrm{CO}_{2}$ [3]. Furthermore, estimated production of the $\mathrm{CO}_{2}$ is 0.82 tons for each ton of cement produced [4] and amounts to $5 \%$ of the world's anthropogenic carbon emissions [5]. Construction is still, however, a cost-plus business, and cement replacement continues to be prevalent because it reduces environmental and financial cost.

Massive concrete elements typically utilize high levels of cement replacement by SCMs to combat high heats of hydration. For this application, Class F fly ash is most commonly used to replace approximately $50 \%$ of the cement, although slags are also effective when used at higher replacement levels [6]. Studies have found that the largest contributor to a reduction in the heat of hydration is the cement replacement level [7]. This effect is characterized by the reduction in heat associated with decreased hydraulic activity. By virtue of dilution, ternary blends of SCMs have also been proven to reduce the heat of hydration when replacing large amounts of cement [7-12]. In practice, however, binary replacements of cement by SCMs are typically used to combat this problem.

\section{Background}

Generation of heat from hydration of cement and associated volume change in mass concrete operations have historically been combatted by replacing a large portion of cement by supplementary cementitious materials. Typically, the procedure is either Class F fly ash or ground granulated blast furnace slag replacing approximately between $30 \%$ and $50 \%$ of the cement. Although metakaolin has been present in concrete literature for decades, little work has been completed to explore its possible benefits inside ternary cementitious blends.

Binary replacements by either fly ash or slag are effective in mitigating high heat of hydration, however, this approach is susceptible to material shortages. There is a tangible risk of the coal market being unable to sustain the current volume of fly ash usage in U.S concrete, particularly in the state of Georgia. Natural gas produces less emissions and is cheaper as a fuel source, and heightened regulations have increased the cost of collecting fly ash. Fly ash is an important SCM used in mitigating deleterious cracking due to the large thermal gradients in mass concrete, and the inability to obtain fly ash would have repercussions on mass concrete placements across the U.S. It is therefore important to evaluate alternative SCMs, as well as SCMs in ternary combinations.

Recent research demonstrated the reduced heat liberation of ternary cementitious blends incorporating metakaolin and slags [8,9]. Studies have also shown increased performance of these mixtures in mechanical tests $[13,14]$ and improved pore properties $[15,16]$. However, comprehensive studies on the behavior of ternary cementitious blends and their long-term performance (or durability) must be evaluated to determine the efficacy and limits of such usage in concrete mixtures.

\section{Research Significance and Objectives}

Ternary mixtures including metakaolin have the potential of reducing the heat of hydration while maintaining mechanical strength, increasing the durability, and improving dimensional stability. While research has been conducted demonstrating the ability of ternary blends of metakaolin and slag to reduce the heat of hydration $[9,10]$, comprehensive studies evaluating the mechanical properties, durability, and dimensional stability of these mixtures have not been conducted. Moreover, studies have not yet been conducted comparing the performance using various commercially-available metakaolin and blast furnace slag products. Blast furnace slag is for short referred to as 'slag' for the remainder of 
this study. This evidence would be crucial to the adoption of ternary blends of metakaolin and slag in ready-mix concrete operations, as product-dependent performance would present a risk in its usage.

The research aims of this paper are two-fold:

- To determine if ternary blends of cementitious materials provide improved performance including durability and dimensional stability.

- To compare the performance of three commercially-available MKs in ternary cementitious blends.

Therefore, the ultimate goals of this study are to explore the efficacy of a ternary metakaolin blends as an alternative to high volume fly ash, and secondarily to provide recommendations for its usage in concrete.

\section{Materials and Experimental Plan}

Fly ash is a versatile SCM in that it is able to improve the fresh properties of concrete, increase durability, as well as reduce liberated heat in mass concreting [17]. It is for this reason that it is so widely used. The experimental study conducted in this paper will include a typical drilled shaft concrete design (mass pour) as a performance benchmark. As will be discussed, this mixture constitutes a $45 \%$ replacement of cement by class F fly ash. To control the dilution effect, ternary SCM combinations shall also replace a portion of cement equaling $45 \%$. Literature indicates that the heat of hydration is minimized at a $45 \%$ replacement when replacements by metakaolin and slag are $15 \%$ and $30 \%$ of the cement content, respectively [9]. Therefore, all combinations of metakaolin and slag in this study shall be $15 \%$ and $30 \%$ of the cement content, respectively. Binary mixtures including $30 \%$ slag are also included to serve as additional benchmarks for performance.

\subsection{Materials}

\subsubsection{Metakaolin}

Three commercially available metakaolin (MK) products are evaluated. The first (MK1), second (MK2), third product (MK3) is sourced from Sandersville, Georgia, Aiken, South Carolina, and Sandersville, Georgia, respectively. All MK products considered in this study are high-reactivity metakaolins (HRMs) that conform to ASTM C 618 [18]. The consensus within the literature is that a HRM should contain $\mathrm{SiO}_{2}+\mathrm{Al}_{2} \mathrm{O}_{3}+\mathrm{Fe}_{2} \mathrm{O}_{3} \geq 90 \%$ by weight. As all MKs evaluated in this paper are high-reactivity with an average particle size of $1.3 \mu \mathrm{m}(<1 \%$ residue on $45 \mu \mathrm{m}$ sieve), they will simply be referred to as MKs. The reactivity of MK entirely depends on the kaolin's purity, and the percentage of kaolinite that is dehydroxylated during calcination (amorphous alumina and silica). However, technical data sheets provided by the product vendors typically contain a breakdown of oxides by weight and material fineness. Thus, these two parameters are typically cited as predictors of performance. A combination of physical and chemical characteristics of the MK products selected in this study are found in Table 1. These properties are taken from products' material specifications provided by manufacturers. Pictures of each product are presented in Figure 1, noting that the second product has a slightly brown coloration. Otherwise, the 3 products are difficult to visually tell apart.

\subsubsection{Blast Furnace Slag}

Two, grade 120, commercially available slag (SL) products were used in this study. They are denoted as 'SLa' and 'SLb'. As with metakaolin products, the chemical composition and physical characteristics are important in understanding slag behavior once inside the concrete and are presented in Table 1. 
Table 1. Chemical and physical properties of materials.

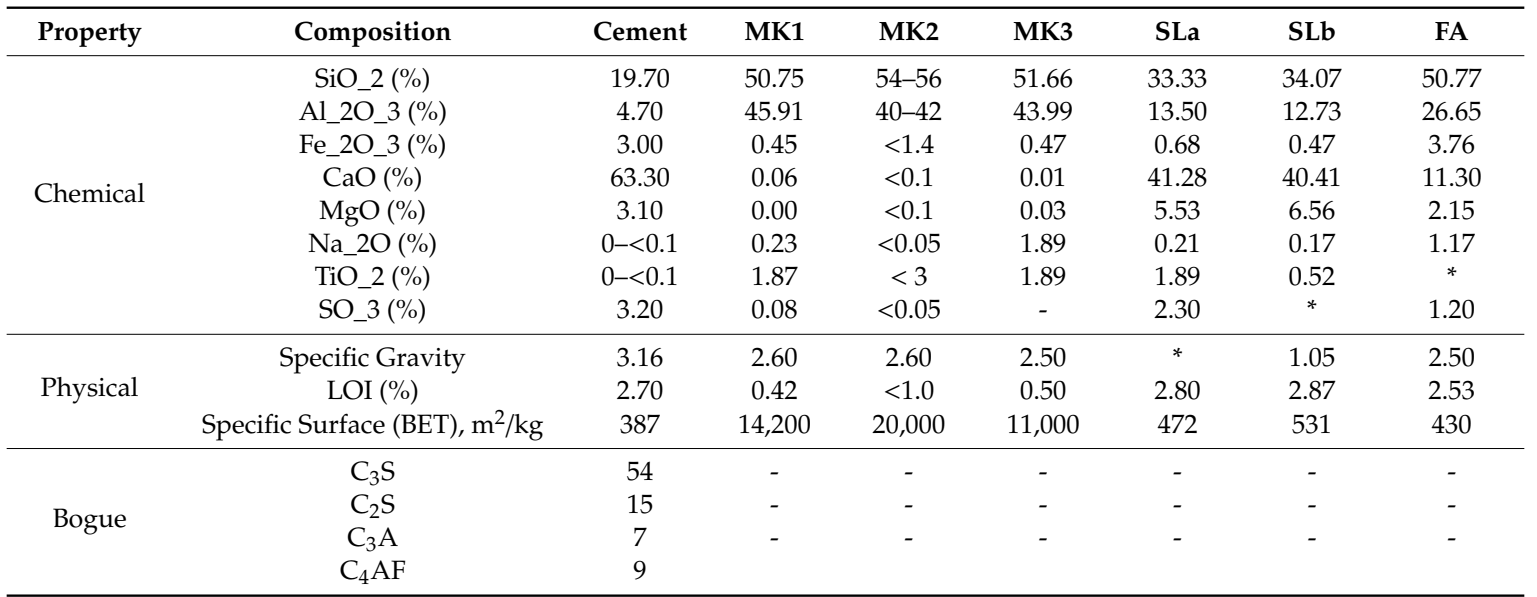

Note: * Material data not provided; - Material data not applicable.

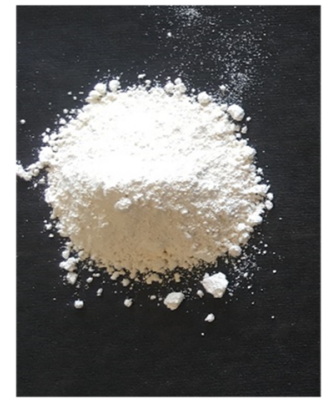

(a)

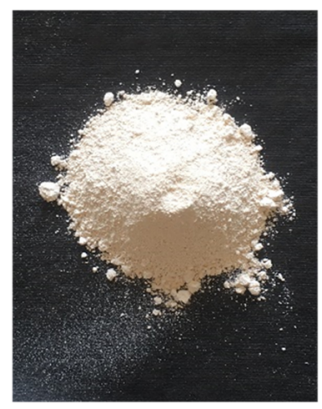

(b)

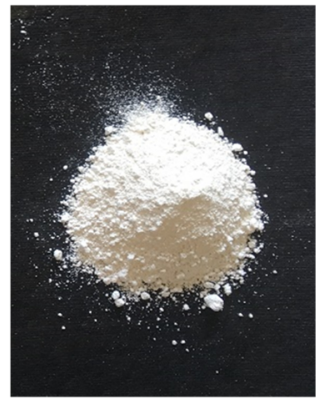

(c)

Figure 1. Sample of metakaolin products (a) MK1; (b) MK2; (c) MK3.

\subsubsection{Fly Ash and Cement}

The fly ash (FA) is an ASTM C618 [18] Class F FA and is a raw material $(<34 \%$ retained on the $0.044 \mathrm{~mm}$ sieve). Pertinent physical and chemical properties for the FA is also included in Table 1 . Finally, a Type I/II Portland cement conforming to ASTM C150 [19] was used for all concrete and mortar mixtures. The cement is local to Atlanta, Georgia. Table 1 lists the physical and chemical characteristics, as well as the Bogue phase composition.

\subsubsection{Aggregates and Chemical Admixtures}

Aggregates conforming to ASTM C33 [20] were used in all concrete and mortar mixtures. The coarse and fine aggregates are sourced from Watkinsville, Georgia and Athens, Georgia, respectively. Neither aggregate is known to be reactive. The coarse aggregate is graded granite stone, and the size of aggregate used is the standard size \#57 (NMAS 1" or $2.54 \mathrm{~mm}$ ). The fine aggregate material contains $100 \%$ of particles that passes the $9.5 \mathrm{~mm}(3 / 8 \mathrm{inch})$ sieve and less than $3 \%$ that passes the $75 \mu \mathrm{m}$ (No. 200) sieve. Water used for mixing was potable tap water. Finally, a PCE-based (polycaboxylate ether) superplasticizer was used for the mixtures ( $33 \%$ solids).

\subsection{Mixture Design}

Concrete mixture proportions are based on a drilled shaft design that incorporates a high volume of FA to reduce heat of hydration and cost. The mixture design is found in Table 2. The total cementitious content for each mixture is $422 \mathrm{~kg} / \mathrm{m}^{3}$. The water-to-cementitious material $(\mathrm{w} / \mathrm{cm})$ ratio is 0.43 , and the coarse aggregate fraction is $753 \mathrm{~kg} / \mathrm{m}^{3}$. All concrete mixtures incorporate a target air content equal to $4 \%$ SCMs replace a percentage of cement by weight. The weight of sand varied by mixture and 
was determined according to the absolute volume method as in ACI 211. Saturated surface-dry (SSD) mixture proportions are listed in Table 2.

Table 2. Saturated surface-dry (SSD) proportions per $\mathrm{m}^{3}$ of mixture.

\begin{tabular}{|c|c|c|c|c|c|c|c|c|c|}
\hline Mixture & $\begin{array}{c}\text { Cement } \\
\text { (kg) }\end{array}$ & $\begin{array}{l}\text { Meta-Kaolin } \\
\text { (kg) }\end{array}$ & $\begin{array}{l}\text { Slag } \\
\text { (kg) }\end{array}$ & $\begin{array}{l}\text { Fly Ash } \\
\text { (kg) }\end{array}$ & $\begin{array}{c}\text { Coarse } \\
\text { Aggregate } \\
(\mathrm{kg})\end{array}$ & $\begin{array}{c}\text { Fine } \\
\text { Aggregate } \\
(\mathrm{kg})\end{array}$ & $\begin{array}{l}\text { Water } \\
\text { (kg) }\end{array}$ & Air (\%) & $\begin{array}{c}\text { Super-Plasticizer } \\
(\mathrm{mL} / \mathrm{kg} . \mathrm{cm})\end{array}$ \\
\hline Control & 422 & 0 & 0 & 0 & 985 & 723 & 182 & 4 & 2.2 \\
\hline SLa-30 & 295 & 0 & 126 & 0 & 985 & 713 & 182 & 4 & 2.2 \\
\hline SLb-30 & 295 & 0 & 126 & 0 & 985 & 713 & 182 & 4 & 2.7 \\
\hline FA- 45 & 232 & 0 & 0 & 190 & 985 & 663 & 182 & 4 & 0.5 \\
\hline MK1-15_SLa-30 & 232 & 63 & 126 & 0 & 985 & 702 & 182 & 4 & 4.8 \\
\hline MK1-15_SLb-30 & 232 & 63 & 126 & 0 & 985 & 702 & 182 & 4 & 4.8 \\
\hline MK2-15_SLa-30 & 232 & 63 & 126 & 0 & 985 & 702 & 182 & 4 & 4.6 \\
\hline MK2-15_SLb-30 & 232 & 63 & 126 & 0 & 985 & 702 & 182 & 4 & 4.8 \\
\hline MK3-15_SLa-30 & 232 & 63 & 126 & 0 & 985 & 702 & 182 & 4 & 4.6 \\
\hline MK3-15_SLb-30 & 232 & 63 & 126 & 0 & 985 & 702 & 182 & 4 & 4.6 \\
\hline
\end{tabular}

Mortar specimens were batched and tested according to ASCM C1012 [21] and C1567 [22] for sulfate reactivity and alkali-silica reactivity, respectively. Mixture proportions differed for these tests as per the testing standards.

For the sulfate mixtures, cementitious material to sand ratios were $1: 2.75 \mathrm{and} w / \mathrm{cm}$ ratios were 0.485 . Cement replacements by SCMs were by weight as in the concrete mixtures. Finally, a superplasticizer was included to control for significant workability difference between mixtures. This deviation from ASTM C1012 [21] was felt necessary by the authors, as the loss of concrete performance with increasing $\mathrm{w} / \mathrm{cm}$ is exaggerated with metakaolin inclusion [23].

ASR specimens were created according to specific batch weights. A $990 \mathrm{~g}$ quantity of sand was mixed with $440 \mathrm{~g}$ of total cementitious material. $\mathrm{W} / \mathrm{cm}$ ratios were 0.43 . Workability was maintained amongst mixtures by inclusion of a superplasticizer.

\subsection{Batching and Molding}

Concrete mixtures were machine mixed using a portable revolving drum mixer with a $0.35 \mathrm{~m}^{3}$ capacity. Saturated surface dry (SSD) mixture proportions were altered according to the volumetric method to accommodate the moisture condition of the aggregates upon mixing, and then weighed using a scale with a $136 \mathrm{~kg}$ capacity and $0.05 \mathrm{~kg}$ accuracy. Materials were added and mixed per ASTM C192 [24]. The superplasticizer was added to the mixing water and thoroughly agitated before the water was added to the mixer. Contents of the mixer were then discharged into a wheelbarrow so that fresh concrete tests could be performed, and molds were filled. Material from the same batch filled the specimen molds for all hardened concrete tests excluding sulfate and ASR.

Mortar mixtures were mixed using a portable table-top mixer with a nominal capacity of $4.8 \mathrm{~L}$, and according to ASTM C305 [25] mixing procedure. The superplasticizer was added separately after adding water as the paddle rotated. The plastic mixture was then discharged into molds.

\subsection{Concrete Mixture Properties Testing and Procedure}

\subsubsection{Fresh Properties}

After batching, the temperature, air content, slump, and unit weight were measured. The tests for unit weight and air were per ASTM C138 [26] and C231 [27], respectively, while slump was taken per C143. Temperature was measured with a thermometer per ASTM C 1064 [28].

\subsubsection{Mechanical Properties}

Specimens were made according to ASTM C192 [24], and were subjected to curing in a lime bath before testing. Compression cylinders measuring $100 \mathrm{~mm} \times 200 \mathrm{~mm}$ were made for 1, 7, and 28-day strengths. Mixture strengths were taken as the average of three specimen strengths at each testing 
day. The universal testing machine used to break the cylinders had a capacity of $3.5 \mathrm{MN}$, which used neoprene caps for restraints. Cylinders were subject to a loading of 2000 N/s, per ASTM C39 [29].

Tensile strength for concrete was measured two ways: split-cylinder, and MOR. The split cylinder tests were performed on cylinders measuring $100 \mathrm{~mm} \times 200 \mathrm{~mm}$, while the MOR prisms were $150 \mathrm{~mm} \times 150 \mathrm{~mm} \times 550 \mathrm{~mm}$. The testing protocol for each were per ASTM C 496 [30] and C78 [31], respectively. The same universal testing machine was used for the tensile tests as the compressive tests. Specimens were loaded at a constant rate of $130 \mathrm{~N} / \mathrm{s}$. The mixture tensile strengths were the average of three individual specimen strengths at the age of 28 days.

The dynamic modulus of elasticity $\left(E_{d}\right)$ test was performed on cylinders measuring $100 \mathrm{~mm} \times 200 \mathrm{~mm}$ at 28 days of age. Testing equipment measures concrete resonant frequency in the longitudinal direction, which was achieved by the forced resonance method outlined in ASTM C215 [32].

\subsubsection{Durability Tests including Permeability, Sulfate Attack, and ASR}

Tests of durability performed on concretes follow the same laboratory mixing and curing protocol as the specimens in strength testing. Rapid chloride-ion penetrability tests at 28 days of age were used as an indirect measure of the permeability of each SCM combination. Top sections of concrete cylinders $(100 \mathrm{~mm} \times 50 \mathrm{~mm})$ were cut for testing, as this is the most permeable section. RCPT testing lasted for six hours per the ASTM C1202 [21]. The average charge passed by two specimens was taken as the permeability of the mixture.

Protocol outlined in ASTM C1012 [21] was used to test for sulfate resistance of mixtures. Mortar cubes measuring a side length of $50 \mathrm{~mm}$ were batched alongside mortar prisms measuring $25 \mathrm{~mm}$ $\times 25 \mathrm{~mm} \times 280 \mathrm{~mm}$. Both were stored for $24 \mathrm{~h}$ at a temperature of $95^{\circ} \mathrm{F}$. Periodically, the cubes would be tested for compressive strength until the average compressive strength of any two specimens exceeded $20 \mathrm{MPa}$. The mortar prisms were immersed in plastic containers of aqueous solutions of $\mathrm{Na}_{2} \mathrm{SO}_{4}$. Each mortar bar was subjected to exposure to $0.75 \mathrm{~L}$ of solution, at a concentration of $50 \mathrm{~g} / \mathrm{L}$ $\mathrm{Na}_{2} \mathrm{SO}_{4}$. Expansions of the bars were measured at 7, 14, 21, 28, 56, 91, 105, 126, and 168 days in solution. The expansion of each mixture was taken as the average of six specimens. At this concentration, the expansion limit considered to effectively mitigate sulfate attack is $0.1 \%$.

For each ASR mixture, three mortar prisms (same dimensions as sulfate prisms) were batched and burlap cured at $23^{\circ} \mathrm{C}$ for $24 \mathrm{~h}$. At the end of the 24-h curing period, the mortar bars were released from the molds and immersed in tap water elevated to $80^{\circ} \mathrm{C}$. This temperature was maintained for $24 \mathrm{~h}$. After this period, mortar bars were immersed in an aqueous solution of $40 \mathrm{~g} / \mathrm{L}$ maintained at $80^{\circ} \mathrm{C}$. Expansion readings were taken at $1,5,9$, and 14 days after immersion in solution. As with the sulfate test, the maximum expansion that can be interpreted as mitigating the expansion is $0.1 \%$.

\subsubsection{Dimensional Stability Tests including CTE and Drying Shrinkage}

The coefficient of thermal expansion (CTE) was measured on $100 \mathrm{~mm} \times 175 \mathrm{~mm}$ concrete cylinders. The testing followed the protocol outlined in AASHTO T336, which subjected the concrete to three heating and cooling cycles between $10{ }^{\circ} \mathrm{C}$ and $50^{\circ} \mathrm{C}$. An LVDT with a sensitivity of $0.001 \mathrm{~mm}$ detected changes in length as a function of temperature. The average strain per unit temperature change of three specimens was taken as the CTE of any given SCM combination.

Drying shrinkage over a period of nine months was measured for each mixture at an ambient temperature of $22{ }^{\circ} \mathrm{C}$ and a relative humidity of $50 \%$, after an initial 28-day curing period in a lime-saturated bath. The protocol, which is in accordance with ASTM C157 [33], utilized concrete prisms of dimension $100 \mathrm{~mm} \times 100 \mathrm{~mm} \times 280 \mathrm{~mm}$ to measure the average shrinkage of three specimens per mixture. Each prism was suspended from the shelf, and rested on two wooden blocks at either end. Measurements of length change were taken at 32, 25, 42, 56, 84, 140, and 252 days after first batching. 


\section{Results}

\subsection{Fresh Properties}

Table 3 shows the fresh concrete properties for all concrete mixtures. Slumps ranged from $25 \mathrm{~mm}$ ( 1 inch) to $250 \mathrm{~mm}$ (10 inches), and air content typically ranged from $2.6 \%$ to $5.5 \%$. Placement temperatures ranged between $24^{\circ} \mathrm{C}\left(75^{\circ} \mathrm{F}\right)$ and $30^{\circ} \mathrm{C}\left(86^{\circ} \mathrm{F}\right)$.

Table 3. Fresh concrete mixture properties.

\begin{tabular}{|c|c|c|c|c|c|}
\hline Mixture & Slump (cm) & $\begin{array}{c}\text { Air Content } \\
(\%)\end{array}$ & $\begin{array}{l}\text { Unit Weight } \\
\qquad\left(\mathrm{kg} / \mathrm{m}^{3}\right)\end{array}$ & $\begin{array}{l}\text { Plasticizer } \\
\text { Dosage } \\
(\mathrm{mL} / \mathrm{kg} . \mathrm{cm})\end{array}$ & $\begin{array}{c}\text { Temperature } \\
\left({ }^{\circ} \mathrm{C}\right)\end{array}$ \\
\hline Control & 7.6 & $4.1 \%$ & 2346 & 2.15 & 23 \\
\hline SLa-30 & 2.5 & $4.3 \%$ & 2192 & 4.77 & 20 \\
\hline SLb-30 & 2.5 & $3.0 \%$ & 2353 & 4.56 & 28 \\
\hline FA- 45 & 15.2 & $0.0 \%$ & 2340 & 0.50 & 30 \\
\hline MK1-15_SLa-30 & 25.4 & $4.5 \%$ & 2253 & 4.77 & 29 \\
\hline MK2-15_SLa-30 & 4.4 & $3.9 \%$ & 2266 & 2.19 & 23 \\
\hline MK3-15_SLa-30 & 22.9 & $4.5 \%$ & 2186 & 2.67 & 24 \\
\hline MK1-15_SLb-30 & 22.9 & $3.5 \%$ & 2317 & 0.54 & 29 \\
\hline MK2-15_SLb-30 & 9.7 & $3.8 \%$ & 2301 & 4.76 & 29 \\
\hline MK3-15_SLb-30 & 5.1 & $5.0 \%$ & 2321 & 4.55 & 27 \\
\hline
\end{tabular}

\subsection{Mechanical Properties}

\subsubsection{Compressive Strength}

Strength evolutions for all mixtures are found in Figure 2.

Of the two binary mixtures including slag or fly ash, only one mixture achieved a 28-day strength higher than control. The results from slag binary mixtures are presented to see the effect of replacing additional $15 \%$ of MK with cement. SLb-30 exhibited a 28-day compressive strength of $64 \mathrm{MPa}$ (9222 psi), an increase of $18 \%$. Mixtures SLa-30 and FA-45 were $2 \%$ and 51\% weaker in compression than the control, respectively. The rates of strength gain were similar between the two binary slag mixtures, the exception of the results being that SLb-30 was stronger than SLa-30 by slightly over $9 \mathrm{MPa}(1300 \mathrm{psi})$ at one day of age. This was nearly the same difference in strength at 28-days of age.

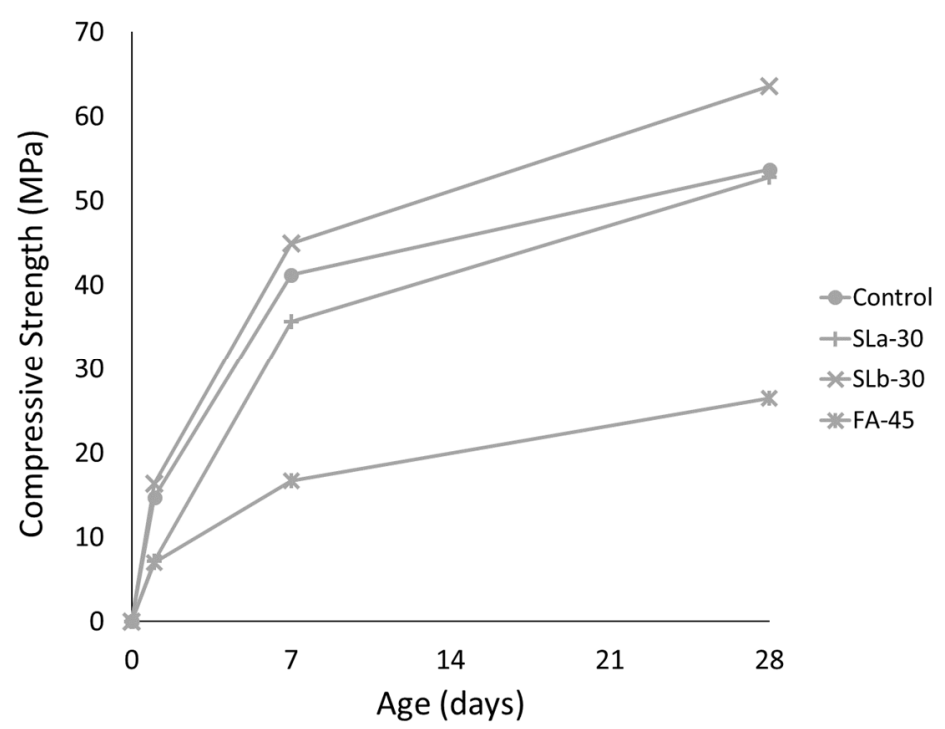

(a)

Figure 2. Cont. 


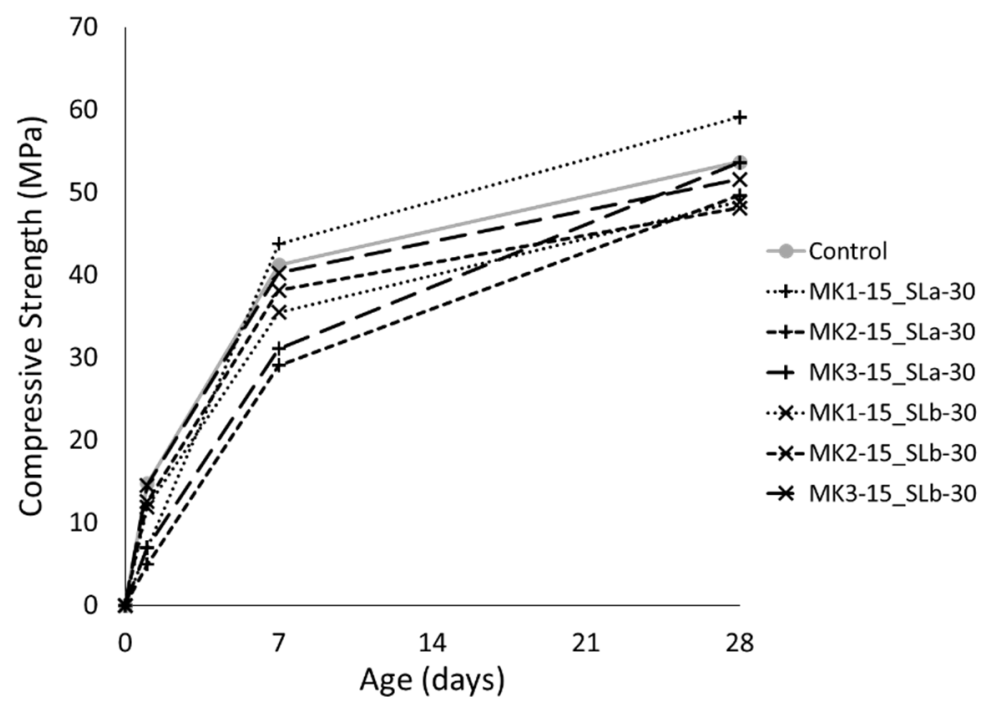

(b)

Figure 2. Compressive strength evolution for (a) non-metakaolin binary SCM, and (b) ternary SCM mixtures.

Of the ternary mixtures, only one mixture had a higher 28-day compressive strength than the control. MK1-15_SLa-30 finished with a compressive strength of $59 \mathrm{MPa}(8570 \mathrm{psi}), 10 \%$ higher than control. MK3-15_SLa-30 finished with a compressive strength very near control, with $54 \mathrm{MPa}$ (7770 psi). One-day strengths were similar or less than control for all ternary concrete mixtures including SLa. Their compressive strengths ranged from $5 \mathrm{MPa}$ (715 psi) to 7MPa (1010 psi). Apart from MK1-15_SLa-30, the 7-day strength for concrete mixtures including SLa were lower than both control and those including SLb. However, after an age of 7 days, all SLa ternary concrete mixtures gained compressive strength at a higher rate than did SLb ternary mixtures and the control.

By contrast, ternary mixtures including SLb did not suffer lower 1-day strengths, ranging between $12 \mathrm{MPa}$ and $14.5 \mathrm{MPa}(1730 \mathrm{psi}$ and $2110 \mathrm{psi}$ ), though they were still lower than control. Moreover, ternary mixtures including SLb exhibited the highest rate of strength gain from 1-7 days but saw less dramatic strength gain after 7 days of age. Overall (excluding MK1-15_SLa-30), the 28-day strength for ternary mixtures ranged from $48 \mathrm{MPa}(6970 \mathrm{psi})$ to $54 \mathrm{MPa}(7769 \mathrm{psi})$.

\subsubsection{Tensile Strength}

The tensile strength results of binary slag and fly ash concrete mixtures, as well as ternary concrete mixtures are found in Figure 3.

Binary slag mixtures were stronger in tension than control. Mixture SLa-30 produced a splitting-tensile strength that was 15\% lower than control, while SLb-30 was 17\% higher than control. MOR values for theses concrete mixtures were both higher than control, ranging between 5.1 and $6.6 \mathrm{MPa}$ (740 and $958 \mathrm{psi}$ ), respectively. The fly ash mixture yielded a strength reduction in splitting-tension and MOR of $24 \%$ and $23 \%$, respectively. Ternary SCM mixtures typically displayed lower tensile strength than control, however, MK1-15_SLa-30 performed similarly to control for both split-tension and MOR. Furthermore, with the exception of MK2-15_SLb-30 split tension results, ternary mixtures incorporating MK1 and MK3 appear to have higher tensile strengths than do ternary mixtures incorporating MK2. Finally, the choice of slag product does not appear to negatively affect the tensile strength of concrete in ternary mixtures. 


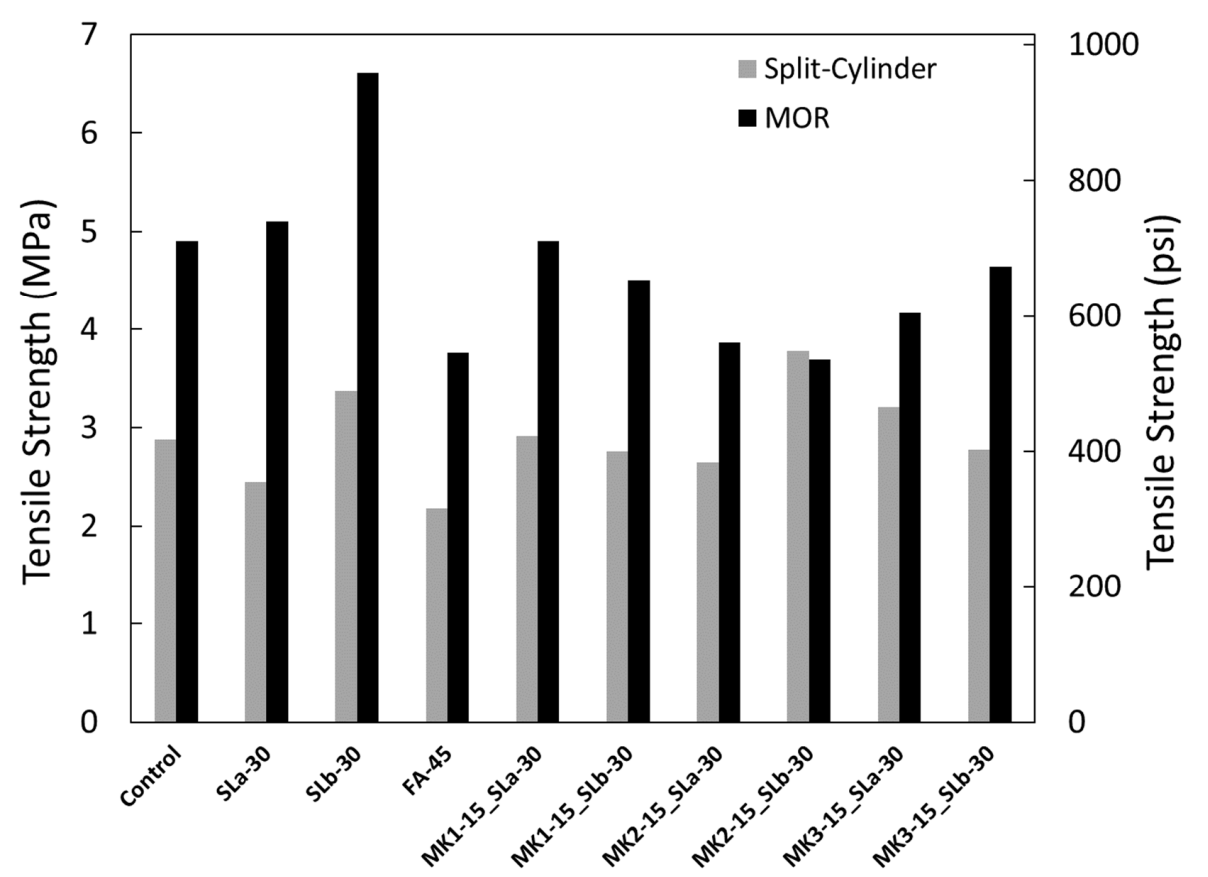

Figure 3. Tensile strength of non-metakaolin binary and ternary SCM mixtures.

\subsubsection{Dynamic Modulus of Elasticity}

Concrete mixtures consisting of binary SCM mixtures (non-metakaolin) and ternary SCM mixtures have their modulus values given in Figure 4. Binary slag concrete mixtures displayed higher dynamic Young's moduli $\left(\mathrm{E}_{\mathrm{d}}\right)$ than the control, while all other mixtures saw a reduction from control. Increases were on the order of $1 \mathrm{GPa}$ and $0.4 \mathrm{GPa}(150 \mathrm{ksi}$ and $60 \mathrm{ksi}$ ) for SLa-30 and SLb-30, respectively. The greatest reduction in the Young's modulus was exhibited by the fly ash mixture, a decrease of $28 \%$ from control. There were no obvious trends among metakaolin or slag products for the ternary concrete mixtures, and reductions in $\mathrm{E}_{\mathrm{d}}$ ranged from $12 \%-22 \%$ with an average reduction of $5.6 \mathrm{MPa}$ (811 ksi).

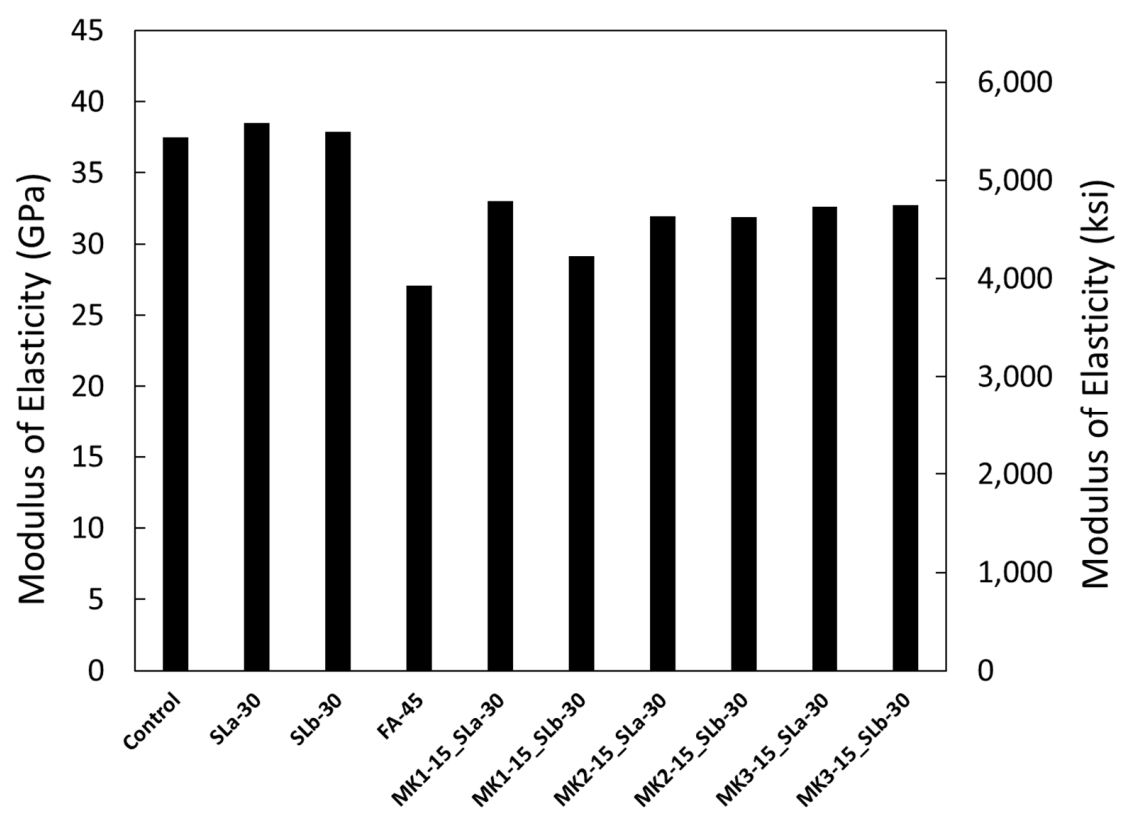

Figure 4. Dynamic Young's modulus of non-metakaolin, binary and ternary SCM mixtures. 


\subsection{Durability}

\subsubsection{RCPT}

Figure 5 shows that only one of three binary SCM concrete mixtures were able to reduce chloride-ion permeability below control. SLa-30 performed similarly to control, while FA-45 nearly reached the 'high' penetrability classification. SLb-30, however, was effective in reducing the total charge passed to 1440 Coulombs (C), earning a 'low' penetrability classification. All ternary SCM concrete mixtures fell below 1000 total coulombs passed. Four mixtures were under $500 \mathrm{C}$. Penetrability classes and results for non-metakaolin binary SCM mixtures and ternary SCM concrete mixtures are shown in Figure 5.

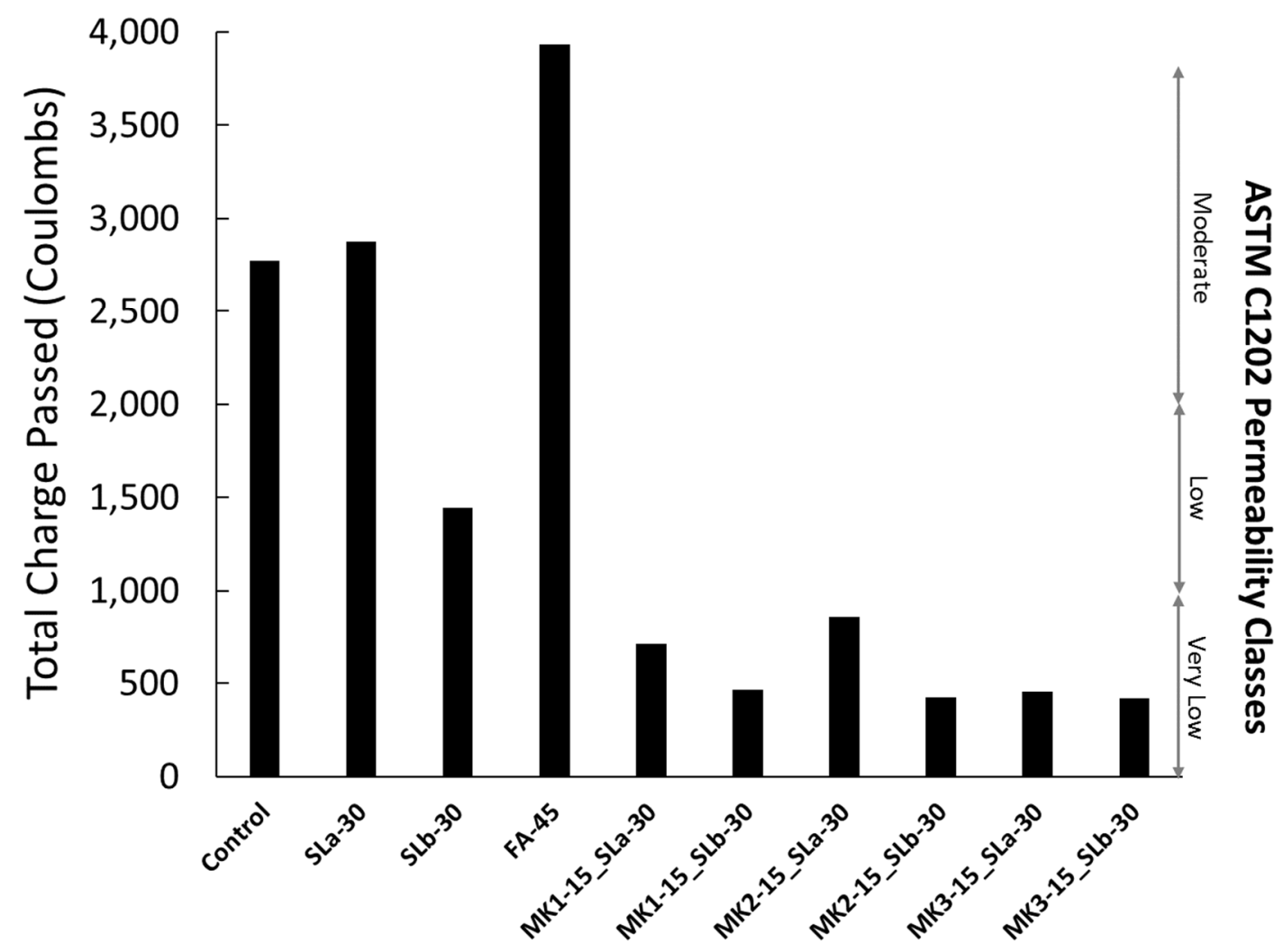

Figure 5. Permeability of non-metakaolin binary and ternary SCM mixtures by RCPT.

\subsubsection{Sulfate Resistance}

Sulfate test results are presented in Figure 6. Fly ash was the only SCM other than metakaolin that was able to sufficiently mitigate mortar expansion for the entire 6-month testing period. In fact, expansion experienced by the binary slag mortars was more accelerated than the control mixture. This was especially true for the mortar incorporating SLa. This is attributed to SLa having both higher $\mathrm{Al}_{2} \mathrm{O}_{3}$ content and the lower fineness. Although the expansion seen by the binary slag mixtures are excessive, it has been recommended that a slag be used at $50 \%$ or higher replacement level to mitigate sulfate attack [34]. In fact, for high $\mathrm{Al}_{2} \mathrm{O}_{3}$ contents (14\% or greater), replacement levels of above $60 \%$ are recommended for this use $[35,36]$. All ternary mixtures were able to mitigate the sulfate expansion, and typically resulted in less than $0.06 \%$ expansion over 6 months.

\subsubsection{ASR Resistance}

All ternary mortars resulted in expansions that were less than $0.03 \%$. Results are presented in Figure 7. As with the sulfate tests, binary slag mortars at a replacement level of $30 \%$ were not sufficient 
to limit the expansion to below acceptable limits (expansions of $0.11 \%$ and $0.12 \%$ ). The binary fly ash mortar exhibited similar expansion to the ternary mixtures.

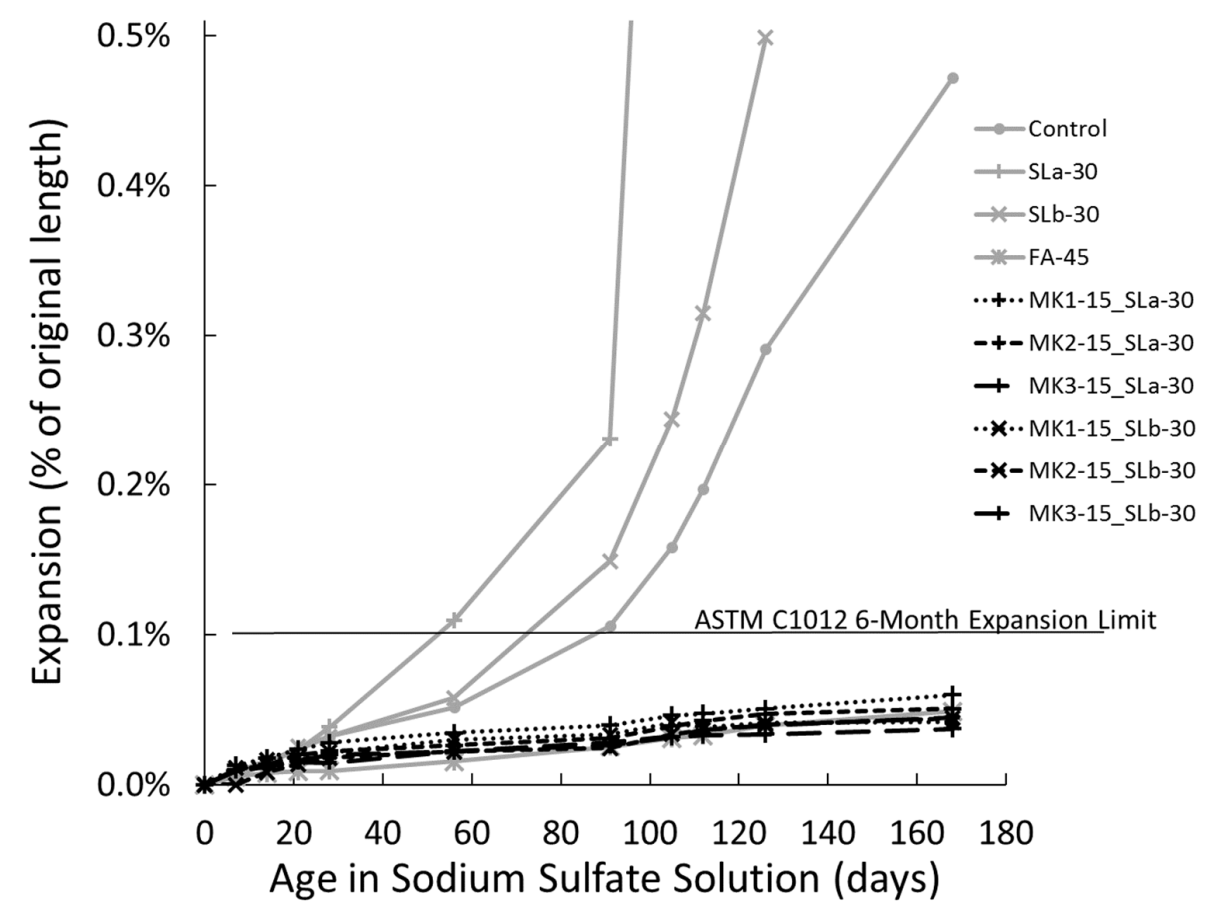

Figure 6. Expansion of non-metakaolin binary and ternary SCM mortar mixtures in sodium sulfate solution.

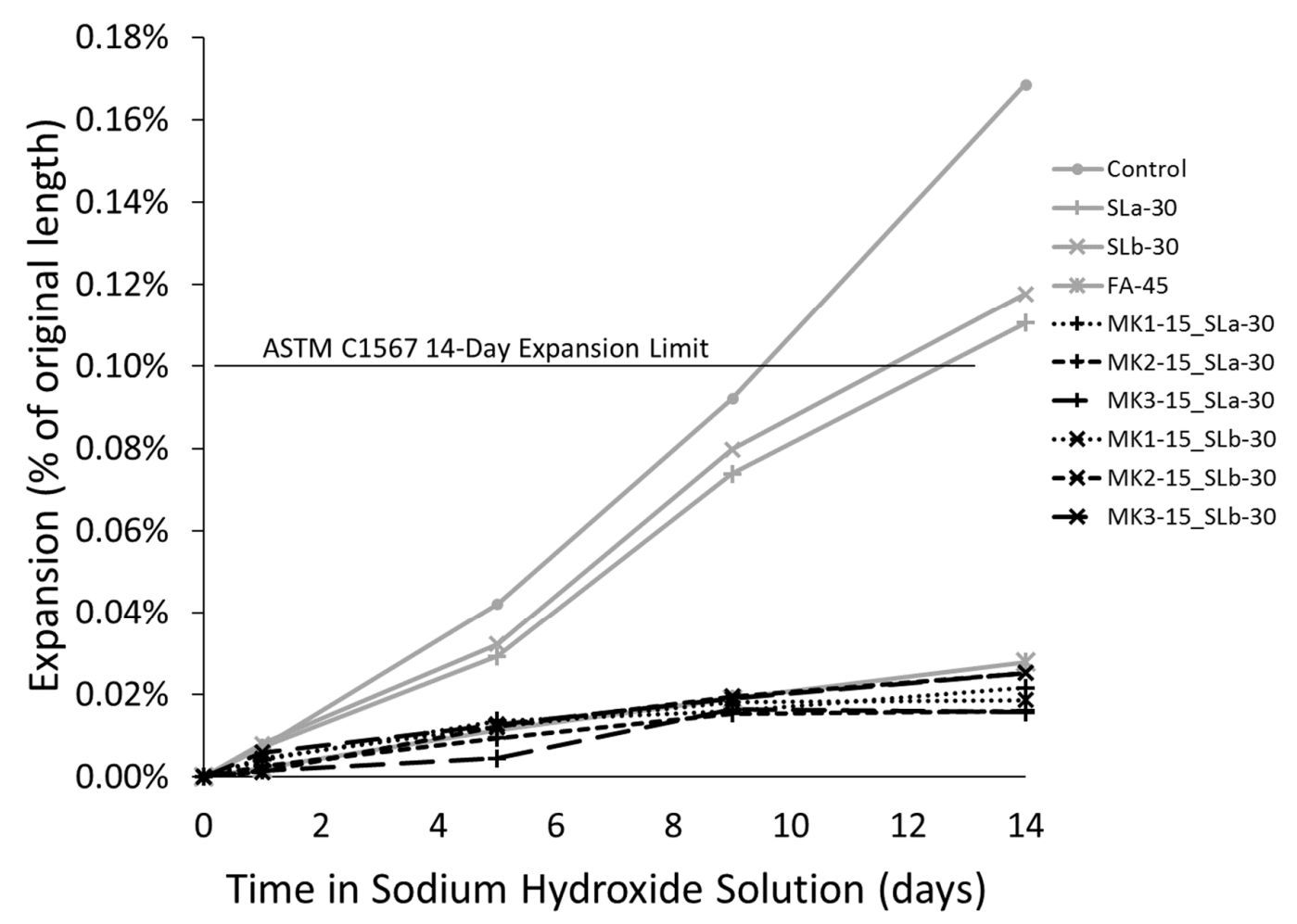

Figure 7. Expansion of non-metakaolin binary and ternary SCM mortar mixtures in sodium hydroxide solution. 


\subsection{Dimensional Stability}

\subsubsection{Drying Shrinkage}

Figure 8 indicates that the ultimate drying shrinkage of ternary concrete mixtures containing MK and SL products were predominantly lower than the control, with an exception of MK1-15_SLa-30. The 224-day drying shrinkage of the control mixture was $0.048 \%$. One mixture, FA- 45 was slightly larger at $0.052 \%$. The overall drying shrinkage of ternary mixtures decreased with the binary mixture, SLb, showing the lowest shrinkage until 112 days. For ternary mixtures including MK1, these values decreased to $0.034 \%$ and $0.042 \%$ for MK1-15_SLa-30 and MK1-15_SLb-30 mixtures, respectively. For ternary mixtures including MK2, shrinkage values decreased to $0.037 \%$ and $0.034 \%$ for MK2-15_SLa-30 and MK2-15_SLb-30, respectively. Similarly, ternary mixtures containing MK3, concrete mixtures decreased to $0.037 \%$ (in MK3-15_SLa-30) or 0.034\% (in MK3-15_SLb-30), which is about $30 \%$ lower than the control.

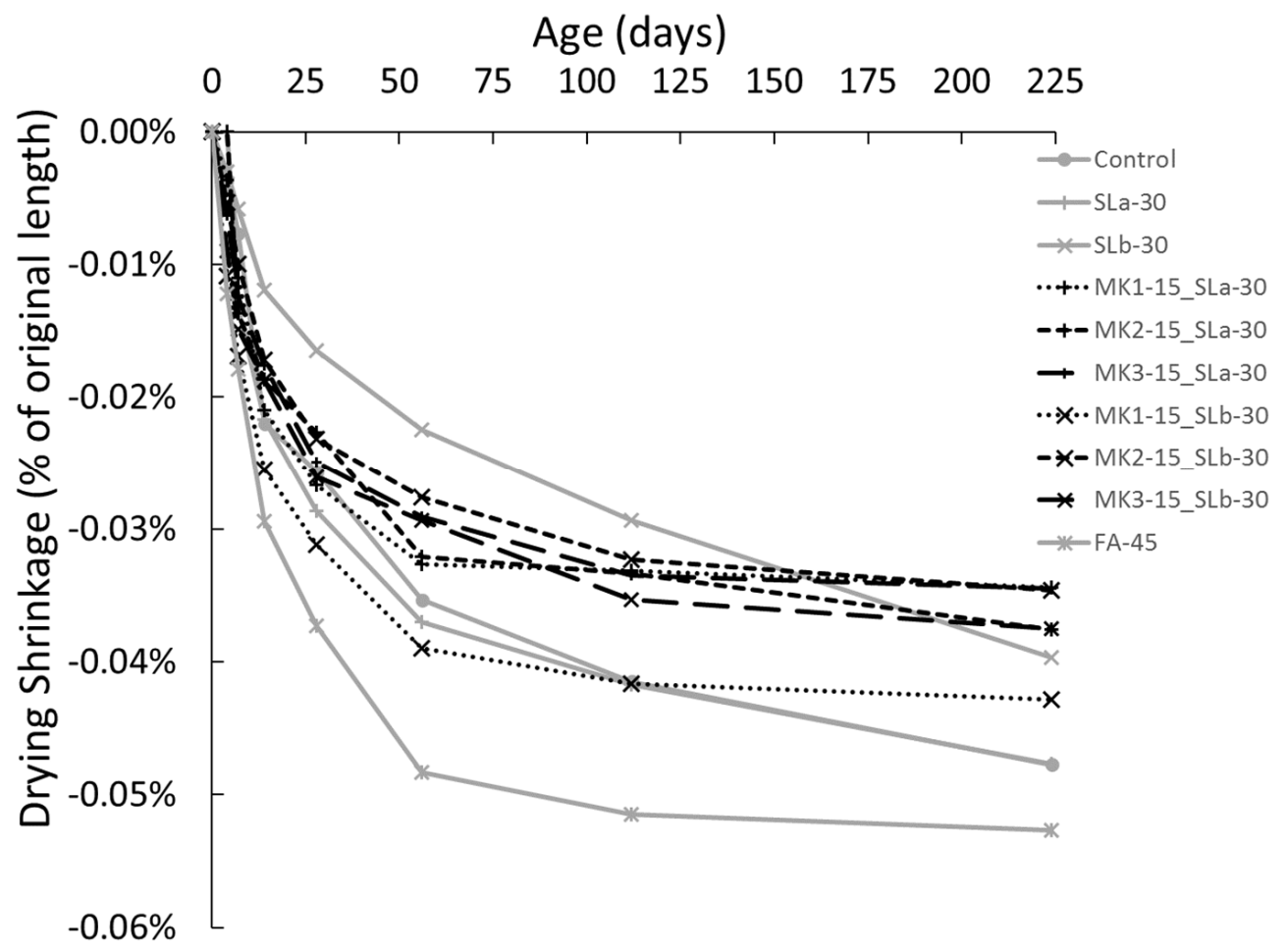

Figure 8. Drying shrinkage of alternate binary and ternary SCM mixtures.

\subsubsection{Coefficient of Thermal Expansion (CTE)}

CTE results are presented in Figure 9. The binary fly ash concrete exhibited a $2 \%$ lower CTE than control. SLa-30 and SLb-30 varied widely from one another at 3\% and 7\% higher than the control, respectively. The latter was the highest CTE seen outside of the binary metakaolin concrete mixtures. MK1-15_SLa-30 saw the lowest CTE in the ternary group with a CTE of $9.73 \times 10^{-6} \mathrm{~mm} / \mathrm{mm} /{ }^{\circ} \mathrm{C}$ $\left(5.40 \times 10^{-6} \mathrm{in} / \mathrm{in} /{ }^{\circ} \mathrm{F}\right.$, an increase of $1 \%$ from control). MK2-15_SLb-30 saw the highest CTE in the ternary group with a CTE of $10.25 \times 10^{-6} \mathrm{~mm} / \mathrm{mm} /{ }^{\circ} \mathrm{C}\left(5.70 \times 10^{-6} \mathrm{in} / \mathrm{in} /{ }^{\circ} \mathrm{F}\right.$, an increase of $\left.7 \%\right)$. As a group the ternary SCM mixtures averaged a CTE of $9.93 \times 10^{-6} \mathrm{~mm} / \mathrm{mm} /{ }^{\circ} \mathrm{C}\left(5.53 \times 10^{-6} \mathrm{in} / \mathrm{in} /{ }^{\circ} \mathrm{F}\right.$, an increase of $3 \%$ ). 


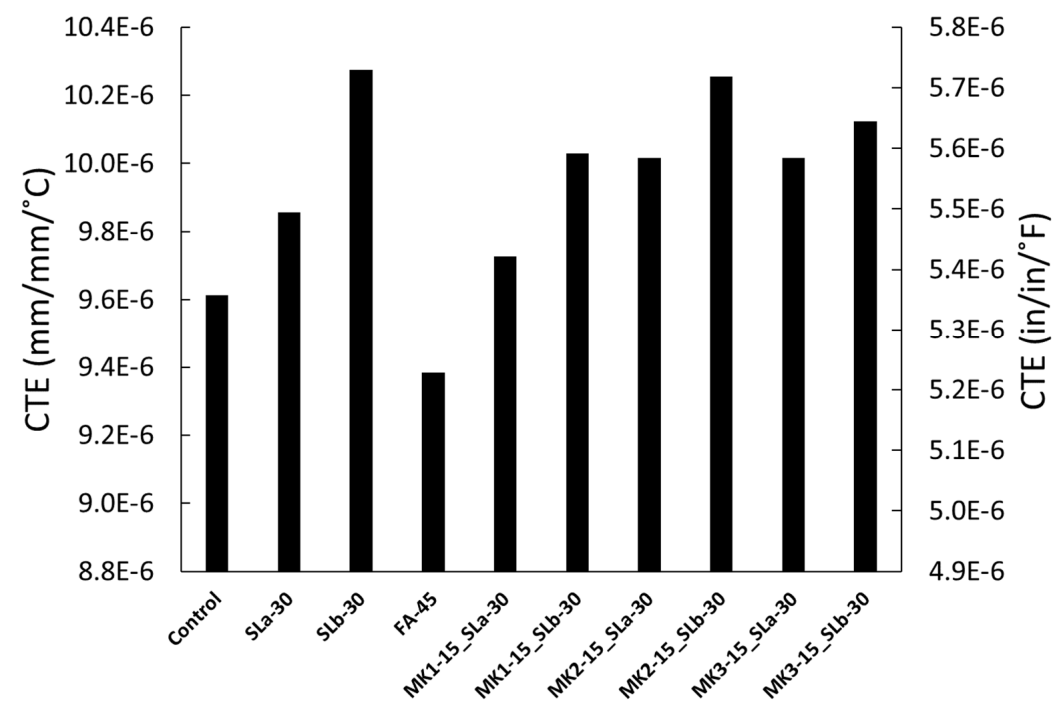

Figure 9. CTEs of binary benchmark and ternary SCM mixtures.

\section{Summary, Discussion, and Recommendations}

\subsection{Summary}

This study evaluated the performance of ternary replacement mixtures. Specifically, a $45 \%$ replacement of cement with 15\% metakaolin and 30\% slag was evaluated for improved concrete performance including durability and dimensional stability. The study was conducted using a wide range of laboratory tests, and Table 4 provides a summary of binary SCM and ternary SCM performance.

Table 4. Summary of alternate binary and ternary mixture performance compared to control (\% change). Note: The up and down arrows indicate increases and decreases, respectively; arrows on both sides indicate insignificant change; and Pass (P)/Fail (F).

\begin{tabular}{|c|c|c|c|c|c|c|c|c|c|c|}
\hline \multirow{2}{*}{$\begin{array}{l}\text { Performance } \\
\text { Category }\end{array}$} & \multirow{2}{*}{$\begin{array}{c}\text { Mixture } \\
\text { Properties }\end{array}$} & \multicolumn{3}{|c|}{ Binary } & \multicolumn{6}{|c|}{ Ternary } \\
\hline & & FA-45 & SLa-30 & SLb-30 & $\begin{array}{r}\text { MK1-15 } \\
\text { SLa-30 }\end{array}$ & $\begin{array}{r}\text { MK1-15 } \\
\text { SLb-30 }\end{array}$ & $\begin{array}{c}\text { MK2-15 } \\
\text { SLa-30 }\end{array}$ & $\begin{array}{r}\text { MK2-15 } \\
\text { SLb-30 }\end{array}$ & $\begin{array}{l}\text { MK3-15 } \\
\text { SLa-30 }\end{array}$ & $\begin{array}{r}\text { MK3-15 } \\
\text { SLb-30 }\end{array}$ \\
\hline \multirow{8}{*}{ Mechanical } & $\begin{array}{c}\text { Compression } \\
\text { (28-day) }\end{array}$ & $\downarrow$ & $\downarrow$ & $\uparrow$ & $\uparrow$ & $\downarrow$ & $\downarrow$ & $\downarrow$ & $\leftrightarrow$ & $\downarrow$ \\
\hline & & $-51 \%$ & $-2 \%$ & $18 \%$ & $10 \%$ & $-9 \%$ & $-8 \%$ & $-10 \%$ & $0 \%$ & $-4 \%$ \\
\hline & $\begin{array}{l}\text { Split-Cylinder } \\
\text { Tension }\end{array}$ & $\downarrow$ & $\downarrow$ & $\uparrow$ & $\uparrow$ & $\downarrow$ & $\downarrow$ & $\uparrow$ & $\uparrow$ & $\downarrow$ \\
\hline & & $-24 \%$ & $-15 \%$ & $17 \%$ & $1 \%$ & $-4 \%$ & $-8 \%$ & $31 \%$ & $11 \%$ & $-4 \%$ \\
\hline & $\begin{array}{l}\text { Modulus or } \\
\text { Rupture }\end{array}$ & $\downarrow$ & $\uparrow$ & $\uparrow$ & $\leftrightarrow$ & $\downarrow$ & $\downarrow$ & $\downarrow$ & $\downarrow$ & $\downarrow$ \\
\hline & & $-23 \%$ & $4 \%$ & $35 \%$ & $0 \%$ & $-8 \%$ & $-21 \%$ & $-25 \%$ & $-15 \%$ & $-5 \%$ \\
\hline & $\begin{array}{c}\text { Dynamic } \\
\text { Modulus }\left(\mathrm{E}_{\mathrm{d}}\right)\end{array}$ & $\downarrow$ & $\uparrow$ & $\uparrow$ & $\downarrow$ & $\downarrow$ & $\downarrow$ & $\downarrow$ & $\downarrow$ & $\downarrow$ \\
\hline & & $-28 \%$ & $3 \%$ & $1 \%$ & $-12 \%$ & $-22 \%$ & $-15 \%$ & $-15 \%$ & $-13 \%$ & $-13 \%$ \\
\hline \multirow{6}{*}{ Durability } & $\begin{array}{c}\text { RCPT } \\
\text { Permeability }\end{array}$ & $\uparrow$ & $\uparrow$ & $\downarrow$ & $\downarrow$ & $\downarrow$ & $\downarrow$ & $\downarrow$ & $\downarrow$ & $\downarrow$ \\
\hline & & $42 \%$ & $4 \%$ & $-48 \%$ & $-74 \%$ & $-83 \%$ & $-69 \%$ & $-85 \%$ & $-84 \%$ & $-85 \%$ \\
\hline & $\begin{array}{c}\text { Sulfate } \\
\text { Resistance }\end{array}$ & - & - & - & - & - & - & - & - & - \\
\hline & & $\mathrm{P}$ & $F$ & $F$ & $\mathrm{P}$ & $\mathrm{P}$ & $\mathrm{P}$ & $\mathrm{P}$ & $\mathrm{P}$ & $\mathrm{P}$ \\
\hline & ASR Resistance & - & - & - & - & - & - & - & - & - \\
\hline & & $\mathrm{P}$ & F & F & $\mathrm{P}$ & $\mathrm{P}$ & $\mathrm{P}$ & $\mathrm{P}$ & $\mathrm{P}$ & $P$ \\
\hline \multirow{4}{*}{$\begin{array}{l}\text { Dimensional } \\
\text { Stability }\end{array}$} & CTE & $\downarrow$ & $\uparrow$ & $\uparrow$ & $\uparrow$ & $\uparrow$ & $\uparrow$ & $\uparrow$ & $\uparrow$ & $\uparrow$ \\
\hline & & $-2 \%$ & $3 \%$ & $7 \%$ & $1 \%$ & $4 \%$ & $4 \%$ & $7 \%$ & $4 \%$ & $5 \%$ \\
\hline & Shrinkage & $\uparrow$ & $\leftrightarrow$ & $\downarrow$ & $\downarrow$ & $\downarrow$ & $\downarrow$ & $\downarrow$ & $\downarrow$ & $\downarrow$ \\
\hline & & $10 \%$ & $0 \%$ & $-17 \%$ & $-28 \%$ & $-10 \%$ & $-21 \%$ & $-27 \%$ & $-28 \%$ & $-21 \%$ \\
\hline
\end{tabular}




\subsection{Discussion of Results}

\subsubsection{No Significant Reduction in Mechanical Strength}

Overall, mechanical strength of ternary mixtures were equal to or just below control. Only one mixture, MK1-15_SLa-30, managed to obtain a 28-day compressive strength higher (10\%) than control. For comparison, the average compressive strength increase over control for all binary MK mixtures was $18 \%$ (ranged from $-9 \%$ to $44 \%$ ). This mixture also had the highest tensile strength of the ternary group, with a MOR equal to that of the control. Although the ternary mixtures out-performed binary concrete mixtures incorporating SLa, concrete mixtures incorporating SLb saw higher compressive (18\% higher than control) and tensile strengths (MOR, 35\% higher than control) than all ternary mixtures. Moreover, SLb-30 exhibited the highest tensile strength of all concrete mixtures tested.

The early-age strength properties of the ternary mixtures appear to be primarily dependent on the slag product used, with the SLb concrete mixtures recording higher 1-day and 7-day strengths. Ternary mixtures incorporating SLa and SLb exhibit nearly the same strength as the binary SLa and SLb binary mixtures, respectively. The difference in compressive strength between concrete mixtures incorporating SLa and SLb continue to be visible up to 7 days (see Figure 2). After this, all ternary mixtures approach compressive strength of the control.

Both MK and slag react pozzolanically with $\mathrm{CH}$ in ternary mixtures, which promotes optimum $\mathrm{CH}$ consumption and higher paste densities. This is evidenced by the durability results presented in this study. However, this does not necessarily ensure higher mechanical strength, as unreacted SCM is most likely present due to competing pozzolanic activity [37]. This explanation is supported by research that showed that as the level of MK inclusion increased, optimum compressive strength was found by reducing slag contents [14]. Although slag is also a latent hydraulic material, its $\mathrm{CaO}$ content is less than that of OPC, and thus less $\mathrm{CH}$ is produced during hydration when slag replaces a portion of cement. In short, in ternary mixtures incorporating 15\% MK and 30\% slag, the slight reduction in compressive strength is a result of less $\mathrm{CH}$ for pozzolanic activity, and more unreacted pozzolan. The increased density of the paste matrix, and additional $\mathrm{C}-\mathrm{S}-\mathrm{H}$ by means of pozzolanic reactions, compensate for the unreacted material.

\subsubsection{Significantly Improved Durability}

The most substantial benefits of the ternary mixtures were seen by the tests of durability, which were most likely the result of high $\mathrm{CH}$ consumption. All ternary mixtures indicated very low permeabilities. Five total mixtures passed less than 500 Coulombs (C), and two ternary mixtures were less than $400 \mathrm{C}$. The ternary mixtures including SLb recorded the lowest permeability, and the highest when combined with MK3 (study low of 419 C). In addition, a sulfate expansion of less than $0.60 \%$ was achieved by only one binary mortar mixture (MK1-20). By contrast, five of six ternary mortars finished over the 6-month testing period under this value. Similarly, all six ternary mortars met ASR expansion criteria. This indicates that, although durability performance varies widely within binary slag and binary MK mortars (see Figures 5-7), ternary mixture durability is consistently high regardless of product combinations.

\subsubsection{Slight Reduced Dimensional Stability}

All ternary concrete mixtures exhibited higher CTE values than the control, however, they were much less those of the binary MK mixtures [38]. As mentioned, increased porosities in FA and slag concrete mixtures have been correlated with decreases in paste CTEs [38]. This is a geometrical property. It is only when high $\mathrm{CH}$ consumption exists, that low-porosity pastes exhibit decreased CTEs from control. This is attributed to the high CTE of $\mathrm{CH}$ being replaced by lower CTE C-S-H now being the dominant effect. Figure 5 indicated that ternary concrete mixtures incorporating SLa have higher penetrability (and by inference, higher porosities) than SLb concrete mixtures on average. Figure 9 indicated that SLa concrete mixtures exhibit lower CTE values than SLb on average. It is 
hypothesized that the reduction in porosity lead to higher CTE values in SLb ternary blends. In ternary blends, the CTE is higher than control but significantly lower than binary MK concrete mixtures, which would most likely have lower porosities than ternary concrete mixtures. Overall, CTEs of ternary concrete mixtures were well below the $10 \times 10^{-6} \mathrm{~mm} / \mathrm{mm} /{ }^{\circ} \mathrm{C}$ limit for acceptable performance in jointed concrete pavements [39] and other mass concrete elements [40].

\subsection{Recommendations for Usage}

Binary mixtures including MK show dramatic benefits in resistance to chemical attack and durability [38], however, ternary mixtures including metakaolin (MK) and slag (SL) also see these benefits. If mechanical strengths need only be similar to a control mixture (pertaining to ordinary Portland cement), it is recommended that a ternary mixture be used. Ternary mixtures see additional benefits above binary MK mixtures:

- $\quad$ Lower coefficient of thermal expansion (CTE)

- Lower heat of hydration $[9,38]$

- Increased resistance to chemical attack

- Reduced permeability

It should be recognized that the durability of ternary mixtures is consistently high regardless of metakaolin and slag product combinations, whereas the performance of binary mixtures was product dependent [38].

\section{Conclusions}

The performance of ternary blended mixtures including metakaolin (MK) and blast furnace slag (SL) is reported through a wide range of laboratory tests. Major findings from this study are:

- All concrete mixtures incorporating MK as a replacement of cement require a high dosage of superplasticizer $(\geq 4 \mathrm{~mL} / \mathrm{kg}$ of cementitious material, or $6.1 \mathrm{oz} . / \mathrm{cwt})$.

- Ternary concrete mixtures using MKs and slags ( $15 \% \mathrm{MK}+30 \%$ slag) tend to perform similarly to one another and control in both compression and tension at 28 days of age. Early-age strength characteristics of the ternary mixtures resemble the early-age strength characteristics of the $30 \%$ mixture using the same slag.

- Ternary concrete mixtures using MKs and slags exhibit very high resistance to chemical attack and very low chloride-ion penetrability. All combinations of commercially-available products performed similarly to one another.

- Ternary concrete mixtures using commercially-available metakaolin and slag products result in increased coefficient of thermal expansion (CTE) values, although much lower than binary MK CTEs previously studied. Values were near threshold value of $10 \times 10^{-6} \mathrm{~mm} / \mathrm{mm} /{ }^{\circ} \mathrm{C}$ reported to be deleterious in jointed concrete pavements and other mass concrete elements.

- Drying shrinkage was lowered from control by ternary mixtures and was on average lower than the shrinkage of the binary MK mixtures.

\section{Future Work}

A time history of the CTEs should be studied if ternary mixtures are to be used in mass concrete placements. A previous study [9] has reported the reduced heat of hydration in these ternary mixtures. The relationship between CTE and the extent of temperature-induced cracking should be of future interest. Finally, varying replacement levels and proportions of metakaolin and slag should be considered in future work. A microstructural analysis including SEM/EDS on mixtures is strongly recommended to investigate the observed interactions. 
Author Contributions: The authors confirm contribution to the paper as follows: methodology, M.S.S., M.G.C., S.A.D.; experimental work, M.S.S., M.G.C.; data analysis and paper writing, M.S.S., M.G.C., S.A.D. All authors have read and agreed to the published version of the manuscript.

Funding: The study presented in this paper was conducted by the University of Georgia under the auspices of the Georgia Department of Transportation (GDOT) Research Projects 16-16 and 16-30 and thus funded by GDOT.

Acknowledgments: The authors extend our sincere appreciation to GDOT staff and engineers that supported this research. Special thanks to David Jared, Peter Wu, and Gary Wood for their continuous support. The authors greatly appreciate generous material donations made by BASF, ACT, and Thiele/Burgess Pigment as well as Argos and Lehigh Hanson. The funding sponsors had no role in the design, analysis, or interpretation of data. The opinions, findings, and conclusions may not reflect the views of the funding agency or other individuals.

Conflicts of Interest: The authors have no implicit or explicit conflict of interest of any kind in this study.

\section{References}

1. Kosmatka, S.H.; Wilson, M.L. Design and Control of Concrete Mixtures, 15th ed.; Portland Cement Association: Skokie, IL, USA, 2011.

2. Gibbs, M.J.; Soyka, P.; Conneely, D.; Kruger, M. $\mathrm{CO}_{2}$ Emissions from Cement Production. Good Practice Guidance and Uncertainty Management in National Greenhouse Gas Inventories. 2000, pp. 175-182. Available online: https://www.ipcc-nggip.iges.or.jp/public/gp/bgp/3_1_Cement_Production.pdf (accessed on 28 January 2020).

3. Gale, J.; Bradshaw, J.; Chen, Z.; Garg, A.; Gomez, D.; Rogner, H.-H.; Simbeck, D.; Williams, R. Chapter 2 Sources of $\mathrm{CO}_{2}$. In IPCC Special Report on Carbon Dioxide Capture and Storage; Cambridge University Press: Cambridge, UK, 2004.

4. Flower, D.J.M.; Sanjayan, J.G. Green house gas emissions due to concrete manufacture. Int. J. Life Cycle Assess. 2007, 12, 282. [CrossRef]

5. Uwasu, M.; Hara, K.; Yabar, H. World cement production and environmental implications. Environ. Dev. 2014, 10, 36-47. [CrossRef]

6. Gajda, J.; Association, P.C. Mass Concrete for Buildings and Bridges; Portland Cement Association: Skokie, IL, USA, 2007.

7. Hu, X.; Shi, C.; Shi, Z.; Tong, B.; Wang, D. Early age shrinkage and heat of hydration of cement-fly ash-slag ternary blends. Constr. Build. Mater. 2017, 153, 857-865. [CrossRef]

8. Boháč, M.; Palou, M.; Novotný, R.; Másilko, J.; Všianský, D.; Staněk, T. Investigation on early hydration of ternary portland cement-blast-furnace slag-metakaolin blends. Constr. Build. Mater. 2014, 64, 333-341. [CrossRef]

9. Hamid, H.; Chorzepa, M.; Sullivan, M.; Durham, S.; Kim, S. Novelties in material development for massive concrete structures: Reduction in heat of hydration observed in ternary replacement mixtures. Infrastructures 2018, 3, 8. [CrossRef]

10. Mohd Nasir, N.A. Hydration of the Combinations of Ground Granulated Blast Furnace Slag Cements. Aust. J. Basic Appl. Sci. 2014, 8, 5.

11. Snelson, D.G.; Wild, S.; O'Farrell, M. Heat of hydration of Portland Cement-Metakaolin-Fly ash (PC-MK-PFA) blends. Cem. Concr. Res. 2008, 38, 832-840. [CrossRef]

12. Yang, K.-H.; Moon, G.-D.; Jeon, Y.-S. Implementing ternary supplementary cementing binder for reduction of the heat of hydration of concrete. J. Clean. Prod. 2016, 112, 845-852. [CrossRef]

13. Dadsetan, S.; Bai, J. Mechanical and microstructural properties of self-compacting concrete blended with metakaolin, ground granulated blast-furnace slag and fly ash. Constr. Build. Mater. 2017, 146, 658-667. [CrossRef]

14. Khatib, J.M.; Hibbert, J.J. Selected engineering properties of concrete incorporating slag and metakaolin. Constr. Build. Mater. 2005, 19, 460-472. [CrossRef]

15. Asbridge, A.; Walters, G.; TR, J. Ternary blended concretes-opc/ggbfs/metakaolin. In International Conference, Concrete across Borders, 1994; Danish Concrete Association: Odense, Denmark, 1994; pp. 547-558.

16. Li, Z.; Ding, Z. Property improvement of Portland cement by incorporating with metakaolin and slag. Cem. Concr. Res. 2003, 33, 579-584. [CrossRef]

17. Khatib, J.; Kayali, O.; Siddique, R. Dimensional Change and Strength of Mortars Containing Fly Ash and Metakaolin. J. Mater. Civ. Eng. 2009, 21, 523-528. [CrossRef] 
18. ASTM C618-17a. Coal Fly Ash and Raw or Calcined Natural Pozzolan for Use in Concrete; ASTM International: West Conshohocken, PA, USA, 2017. [CrossRef]

19. ASTMC150/C150M-18. Portland Cement; ASTM International: West Conshohocken, PA, USA, 2018. [CrossRef]

20. ASTM C33/C33M-18. Standard Specification for Concrete Aggregates; ASTM International: West Conshohocken, PA, USA, 2018. [CrossRef]

21. ASTM C1012/C1012M-18a. Standard Test Method for Length Change of Hydraulic-Cement Mortars Exposed to a Sulfate Solution; ASTM International: West Conshohocken, PA, USA, 2012. [CrossRef]

22. ASTM C1567-13. Test Method for Determining the Potential Alkali-Silica Reactivity of Combinations of Cementitious Materials and Aggregate (Accelerated Mortar-Bar Method); ASTM International: West Conshohocken, PA, USA, 2013. [CrossRef]

23. Paiva, H.; Velosa, A.; Cachim, P.; Ferreira, V.M. Effect of metakaolin dispersion on the fresh and hardened state properties of concrete. Cem. Concr. Res. 2012, 42, 607-612. [CrossRef]

24. ASTM C192/C192M-16a. Standard Practice for Making and Curing Concrete Test Specimens in the Laboratory; ASTM International: West Conshohocken, PA, USA, 2016. [CrossRef]

25. ASTM C305-14. Practice for Mechanical Mixing of Hydraulic Cement Pastes and Mortars of Plastic Consistency; ASTM International: West Conshohocken, PA, USA, 2014. [CrossRef]

26. ASTM C138/C138M-17a. Test Method for Density (Unit Weight), Yield, and Air Content (Gravimetric) of Concrete; ASTM International: West Conshohocken, PA, USA, 2017. [CrossRef]

27. ASTM C231/C231M-17a. Test Method for Air Content of Freshly Mixed Concrete by the Pressure Method; ASTM International: West Conshohocken, PA, USA, 2017. [CrossRef]

28. ASTM C1064/C1064M-17. Test Method for Temperature of Freshly Mixed Hydraulic-Cement Concrete; ASTM International: West Conshohocken, PA, USA, 2017. [CrossRef]

29. ASTM C39/C39M-18. Standard Test Method for Compressive Strength of Cylindrical Concrete Specimens; ASTM International: West Conshohocken, PA, USA, 2017. [CrossRef]

30. ASTM C496/C496M-17. Standard Test Method for Splitting Tensile Strength of Cylindrical Concrete Specimens; ASTM International: West Conshohocken, PA, USA, 2017. [CrossRef]

31. ASTM C78/C78M-18. Standard Test Method for Flexural Strength of Concrete (Using Simple Beam with Third-Point Loading); ASTM International: West Conshohocken, PA, USA, 2017. [CrossRef]

32. ASTM C215-14. Standard Test Method for Fundamental Transverse, Longitudinal, and Torsional Resonant Frequencies of Concrete Specimens; ASTM International: West Conshohocken, PA, USA, 2017. [CrossRef]

33. ASTM C157/C157M-17. Standard Test Method for Length Change of Hardened Hydraulic-Cement Mortar and Concrete; ASTM International: West Conshohocken, PA, USA, 2017. [CrossRef]

34. Hooton, D. Pelletized Slag Cement: Hydraulic Potential and Autoclave Reactivity. Ph.D. Thesis, McMaster University, Hamilton, ON, Canada, 1981.

35. Ogawa, S.; Nozaki, T.; Yamada, K.; Hirao, H.; Hooton, R.D. Improvement on sulfate resistance of blended cement with high alumina slag. Cem. Concr. Res. 2012, 42, 244-251. [CrossRef]

36. Osborne, G.J. The sulphate resistance of portland and blast furnace slag cement concretes. Am. Concr. Inst. Spec. Publ. 1991, 126, 1047-1072.

37. Li, C.; Sun, H.; Li, L. A review: The comparison between alkali-activated slag ( $\mathrm{si}+\mathrm{ca})$ and metakaolin (si + al) cements. Cem. Concr. Res. 2010, 40, 1341-1349. [CrossRef]

38. Shui, Z.-H.; Zhang, R.; Chen, W.; Xuan, D.-X. Effects of mineral admixtures on the thermal expansion properties of hardened cement paste. Constr. Build. Mater. 2010, 24, 1761-1767. [CrossRef]

39. Sabih, G.; Tarefder, R.A. Impact of variability of mechanical and thermal properties of concrete on predicted performance of jointed plain concrete pavements. Int. J. Pavement Res. Technol. 2016, 9, 436-444. [CrossRef]

40. Siang, G.C. Determination of Coefficient of Thermal Expansion (CTE) of 20MPa Mass Concrete Using Granite Aggregate. IOP Conf. Ser. Mater. Sci. Eng. 2017, 217, 012009. [CrossRef]

(C) 2020 by the authors. Licensee MDPI, Basel, Switzerland. This article is an open access article distributed under the terms and conditions of the Creative Commons Attribution (CC BY) license (http://creativecommons.org/licenses/by/4.0/). 